\title{
An Important Application of Pirkle Type $\pi$-Acidic Chiral Stationary Phases: Resolution of Polynuclear A romatic Hydrocarbon Mixtures by Normal-Phase Conventional and Capillary HPLC
}

\author{
Jae Jeong Ryoo

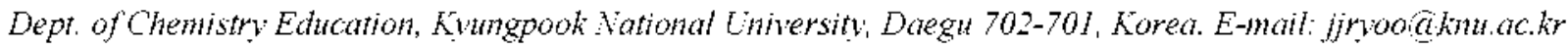 \\ Received August 29, 2008, Accepted Febriary 18, 2009
}

Key Wonds: PAH. Normal phase HPLC. Pirkle tỵpe $\pi$-acidic chiral stationary phase. Capillary HPLC

Polynuclear aromatic hydrocarbons (or polycyclic aromatic hydrocarbon: $\mathrm{PAH}$ ) are stable compounds which have $\pi$ electrons in their ring structure. many of which were confirmed as carcinogens. ${ }^{1.4}$ The most popular method regarding $\mathrm{PAH}$ analy'sis is chromatography. In regard to GC analysis for $\mathrm{PAH}$, this method is expected to obtain enhanced resolved peaks. but it takes a lengthy analysis time with low sensitivity." The most popular chromatographic method regarding PAH analysis is GC-MS. ${ }^{6 . ?}$ Even though it showed a good resolution and high sensitivity. this method also has some limitations, having difficulties in the analy sis of the structural isomers of PAHs and highly contaminated samples. ${ }^{8}$

HPLC is used alone or in conjunction with $\mathrm{GC}$ for exact quantification and shows a high selectivity in the resolution of PAH isomers, such as benzo(a)pyrene and benzo(e)pyrene. In addition. it is very useful in the analysis of various environmental samples. such as industrial and life sewage. without any pretreatment processing. In regard to HPLC analy sis for PAH. the reversed-phase (RP) HPLC mode with an ODS (octadecy lsilane; C 18) column is commonly used. ${ }^{\mathrm{l}, \mathrm{l}}, \mathrm{ll}$ A $C 60$ bonded stationary phase ${ }^{12}$ and a micellar liquid chromatographic method ${ }^{13}$ were used for $\mathrm{PAH}$ analysis by means of the RP-HPLC mode. An amino silica was commonly used stationary phase for PAH analysis by a normal phase (NP) HPLC mode. but separation on the column was not positive. ${ }^{1+}$ A poly'(4-vinylpyridine) grafted silica was recently used as a stationary phase for PAH analysis by NP-HPLC mode and exhibited the best resolution in comparison to previous stationary phases by NP-HPLC. ${ }^{14}$

PAHs contain $\pi$-electron rich aromatic hydrocarbon rings.
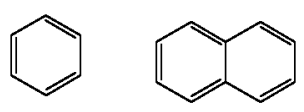

benzene(1) naphthalene(2)

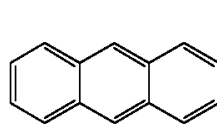

anthracene(3)

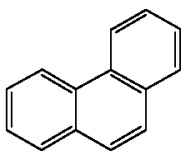

phenanthrene $(4)$<smiles>c1cc2ccc3cccc4ccc(c1)c2c34</smiles>

pyrene(5)

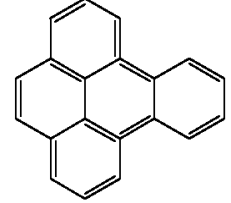

benzo[e]pyrene $(6)$

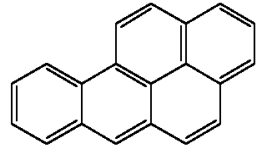

benzo[a]pyrene( 7 )
Figure 1. Stunctures of seven PAHs used in this study
Various kinds of $\pi$-acidic chiral stationary phases were developed in order to resolve the chiral compounds containing $\pi$-electron rich aromatic hydrocarbon rings. ${ }^{15-18}$ In this study: the resolution of seven PAH nixtures were performed by a normal phase HPLC instead of a popularly used reverse phase mode. The $\pi$-electron rich seven PAHs used in this study were benzene. naphthalene, anthracene. phenanthrene. py rene. benzo(a)pyrene, and benzo(e)pyrene. The structures are illustrated in Figure 1. Two domestic $\pi$-acidic chiral stationary phases. (R)-phenylglycinol derived stationary phase (SP I) and (S)-tert-leucinol derived one (SP 2). were used as the normal phase HPLC columns. The stnuctures of two stationary phases are exhibited in Figure 2.

The results were compared with those from a poly (4-vinylpy ridine) grafted silica gel colunn, which exhibited the best resolution regarding the $\mathrm{PAH}$ mixture. ${ }^{1+}$ In addition. the (\$)-tert-leucinol derived chiral stationary phase used in this study was packed into a capillary in order to achieve the separation of the PAH mixtures by a capillary HPLC.

Separation of the seven PAHs, including benzene (benzene. naphthalene, anthracene. phenanthrene. pyrene. benzo(a)pyrene, benzo(e)pyrene) was performed in order to determine their separation patterns on the $\pi$-acidic $(\mathrm{R})$-phenylglycinol and (S)-tert-leucinol derived chiral stationary phases. The results are shown in Figure 3.

As shown in Figure 3 . seven peaks are clearly separated on SP-1, but only five peaks (including an impurity peak) were recorded on SP-2. In comparing the retention times of each<smiles>CCO[Si](CCCNC(=O)OCC(NC(=O)c1cc([N+](=O)[O-])cc([N+](=O)[O-])c1)c1ccccc1)(OC)O[SiH3]</smiles>

SP-1

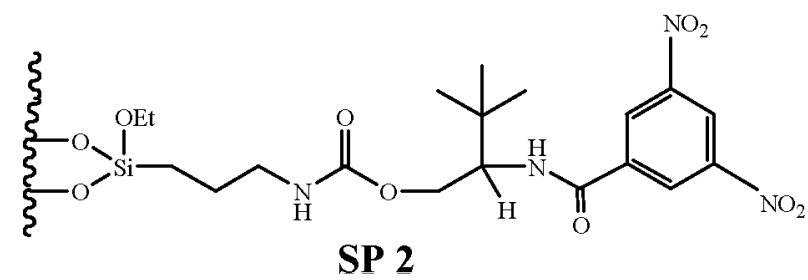

Figure 2. Structures of two stationary phases. 

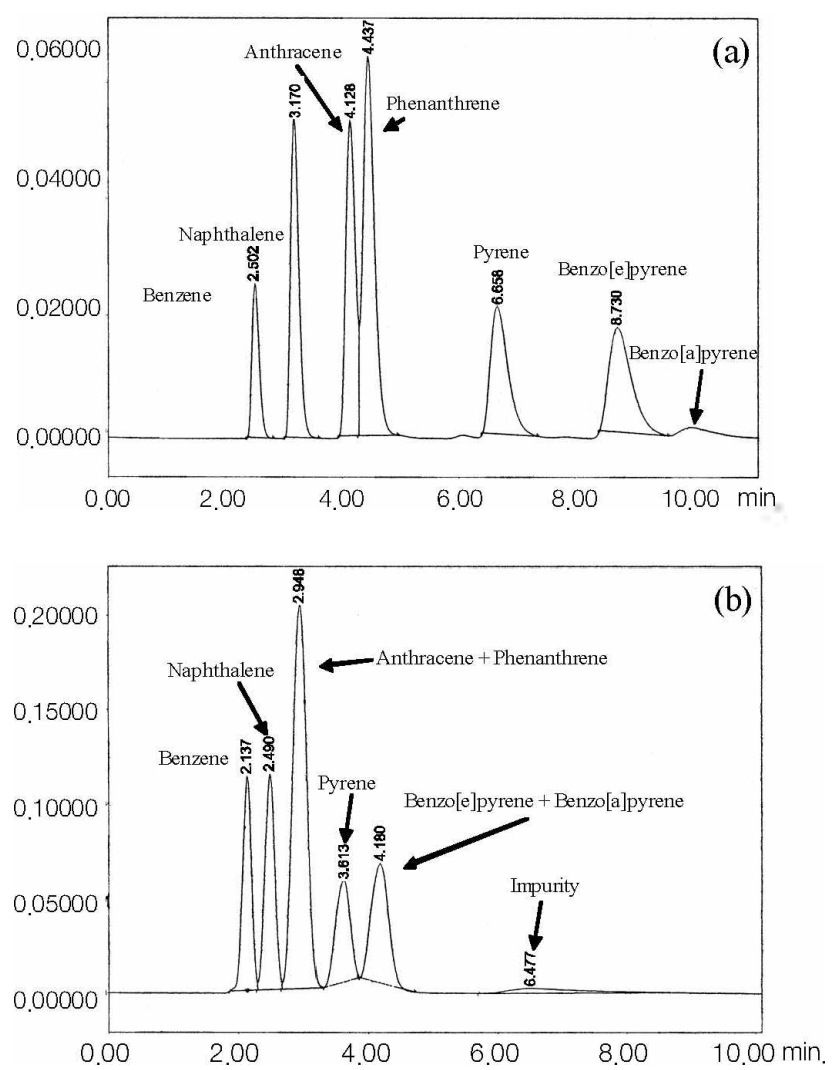

Figure 3. Separation of sesen l'Al ls on $\mathrm{S}^{2}-\mathrm{I}(\mathrm{a})$ and $\mathrm{SI} \mathrm{I}^{2}-2(\mathrm{~b})$. Filuent:

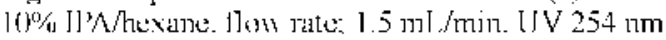

compound. the elution orders were confimed as follows: benzenc. naphthalene. anthracene. phenanthrene. pyrene. benzo(e)pyrene, and benzo(a)pyrene on SP-I, and benzene, naplithalene. antliracene + plienanthrenc. pyrenc. benzo(c)prrene + benzo(a)prene on SP-2. Retention factors $(k)$ and selectivity factors $(\alpha)$ of seven PAHs were calculated based on the chromatograms as illustrated in Figure 3 and shown in Table 1 .

In a recent report, a poly.(4-viny.lpyridinc) grafted silica gel column showed the best resolution among poly st rene-grafted silica. aminopropyl bonded silica an ODS column. and a normal silica column in regards to the resolution of PAH mixtures. Therefore the results of this study were compared with data obtained from the poly (4-vinylpyridine) grafted silica gel column (Table 2). As shown in Table 2. SP 1 cxhibited the best resolution between benzene and naphthalene, and was similar to the poly (4-vinylpy ridine) grafted silica gel column in regards to the resolution between naphthalene and anthracenc, as well as between benzo(c)pyrene and benzo(a)-pyrene. Therefore. SP I can be effectively used in PAH analy sis. The reason for the suecessful resolution of the PAH mixtures on $\pi$-acidic stationary phases could not clearly be verified at this time. However. according to previous results. ${ }^{15,16}$ it is assumed that the resolution was decply influenced by $\pi-\pi$ interaction between the $\pi$-electron rich aromatic hydrocarbon rings in PAHs and the $\pi$-electron deficient 3,5-dinitro group in the $\pi$-acidic stationary phase.

On the other hand. the SP-2 was packed into a capillary for resolving the $\mathrm{PAH}$ mixture by using an environmentally
Table 1. Recention $(h)$ and selectivils lactors $(a)$ lor seren l'Al ts on $S l^{3} l$ and $\left.S\right|^{2} 2$

\begin{tabular}{|c|c|c|c|c|}
\hline \multirow{2}{*}{ PNHS } & \multicolumn{2}{|c|}{$S^{\prime} \mathrm{l}$} & \multicolumn{2}{|c|}{$S P^{\prime} 2$} \\
\hline & $k$ & $1 \pi^{-11}$ & $k$ & $a^{-a}$ \\
\hline Pencene & 0.15 & 3.01 & 0.17 & 2.18 \\
\hline Náphtuthálenc: & 0.46 & 1.96 & 0.37 & 1.68 \\
\hline Anthracene & 0.90 & 1.16 & 0.62 & 1.00 \\
\hline thenanlhrene & 1.04 & 1.99 & 0.62 & 1.58 \\
\hline t'yene & 2.07 & 1.46 & 0.98 & 1.33 \\
\hline |3encoledprente & 3.02 & 1.20 & 1.30 & $1.0 x^{\circ}$ \\
\hline Bertoralpyrene & 3.62 & & $1.400^{6}$ & \\
\hline
\end{tabular}

"Sclectivity lactors of two adjacen peaks for this compound and next raw compound. "This values are different with the ligure 3 . (In Figure 3 , wo peaks of benzolalprene and benzo[e|pyrene are overlapped.) I1 was obained from more that seven times replica experiments.

Table 2. Retention (h) and selectivity factors $(a)$ for selected PNI Js on $S \mathrm{P}^{3} 1, \mathrm{SP}^{2} 2$, and $\mathrm{V} \mathrm{P}^{2}=$

\begin{tabular}{|c|c|c|c|c|c|c|}
\hline \multirow{2}{*}{ PAII } & \multicolumn{2}{|c|}{$s]^{3} \mathrm{I}$} & \multicolumn{2}{|c|}{$51^{\prime} 2$} & \multicolumn{2}{|c|}{ VPי" ביר" } \\
\hline & $k$ & $a^{b}$ & $d$ & a & 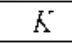 & $a$ \\
\hline 13enrane & 0.15 & 3.01 & 0.17 & 2.18 & 0.17 & 2.6 \\
\hline Naphthalene & 0.46 & 1.96 & 0.37 & 1.68 & 0.35 & 2.17 \\
\hline Anthracerle & 0.90 & & 0.62 & & 0.76 & \\
\hline 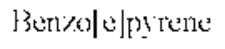 & 3.02 & 1.20 & 1.30 & 1.08 & 3.68 & 1.17 \\
\hline 13enzo|a|prrene & 3.62 & & $1.10^{\prime \prime}$ & & 3.14 & \\
\hline
\end{tabular}

"VI'? is natme of a poly (4-y iny lpy ridine) gratted silica gel. All data were taken trom relerente it. "Selectivity lactors of two adjacent peaks lor this compound and next taw compolind. "These values are diflerent with the ligure 3. See footuote of "lables 1.

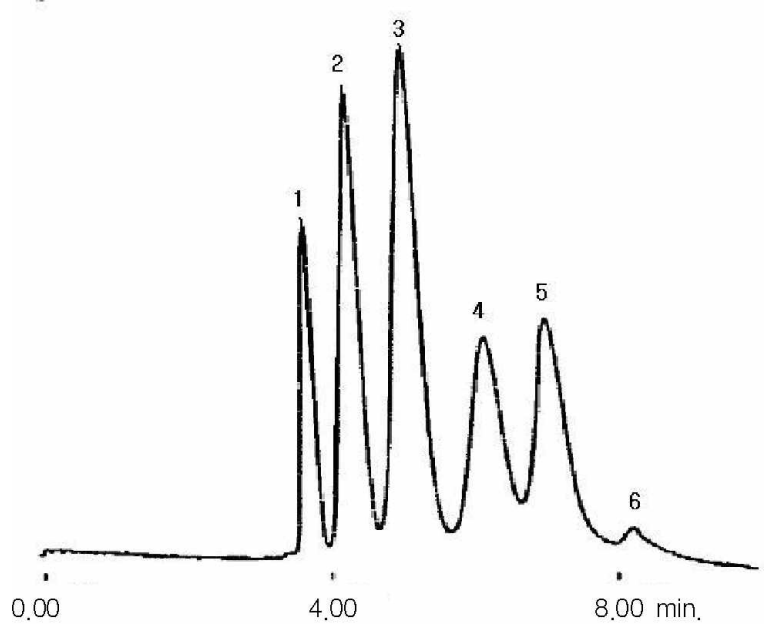

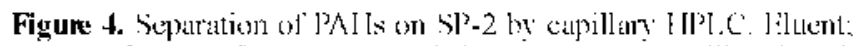

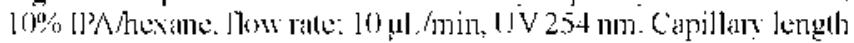
$10 \mathrm{~cm} .0 .25 \mathrm{~mm}$ ID) (1. 13enzene, 2. Naphthalene, 3. Anthracene + phenanthrene, 4. Prene. 5. Benco[s]pyene and Benvolalm rene. 6. impurits )

protective analy sis method. known as capillar. HPL C... ${ }^{19}$ Exen though they showed low resolution pattern, the separation (Higure 4) was similar to the conventional HPLC (Figure 3b). Therefore. if the packing condition was to be improved." the theoretical number and separation could be improved. 
In conclusion, important environmental pollutants, $\mathrm{PAH}$ mixtures were effectively separated in the normal phase HPLC mode by using some Pirkle type chiral columns without any difficulties. This is considered to be an important application of the Pirkle ty'pe $\pi$-acidic chiral stationary phases (CSPs). Therefore. if numerous resolution results have been achieved with many PAH samples and various Pirkle-type CSPs, an effective new stationary phase, which can easily resolve highly complex PAH mixtures under normal phase conditions. can be developed.

\section{Experimental Section}

The HPLC system was consisted with a JASCO (Tokyo. Japan) PU-2080 Plus Intelligent HPLC Pump. a Rheodyne (Cotati, CA, USA) Model 7125 injector with a $20 \mu \mathrm{L}$ sample loop. and a JASCO UV-2075 Plus Intelligent UV/Vis Detector. A Model INJ-P4-100 Valco Micro Injector (sample volume: $100 \mathrm{~nL}$ ) and Knauer Wellchrom Variable UV-VIS Detector K-2501 (Model No. A+180. cell volume: $35 \mathrm{~nL}$ ) were used as injector and detector of the capillary HPLC system. All chromatographic data were obtained by using $10 \%$ 2-propanol in hexane as a mobile phase at a flow rate of $1.5 \mathrm{~mL} / \mathrm{min}(10 \mu \mathrm{L} / \mathrm{min}$ for capillary column). The column void volume was checked by injecting 1,3,5-tri-tert-butylbenzene. an unretained solute obtained from the Aldrich Chemical $\mathrm{Co}$. All reagents and test chiral samples used in this study were obtained from the Aldrich Chemical $\mathrm{Co}$. Solvents for HPLC analy'sis were purchased from the Merck Chemical Co. All testing PAHs were obtained from the Aldrich Chemical $\mathrm{Co}$. and randomly selected in this laboratory: The mixed samples were prepared by dissolving approximately 5 mg or $5 \mu \mathrm{L}$ of each compound into $10.0 \mathrm{~mL}$ of dichloromethane. The injection volume was $3 \mu \mathrm{L}$ ( $1 \mu \mathrm{L}$ for capillary HPLC). The stationary phases used in this study were the same as used in previous work. ${ }^{15}$

A Model PU-2080 Plus Intelligent pump (JASCO, Tokyo. Japan) was used for slurry packing of the capillary column $(0.25 \mathrm{~mm}$ ID. $10 \mathrm{~cm}$ length). A capillary column washer was purchased from the Alltech Korea (Seoul, Korea). Preparation of the capillary column was completed by following procedures outlined in the previous study. ${ }^{19}$

Acknowledgments. This work was supported by the Korea Research Foundation Grant (KRF-2006-311-C00420).

\section{References}

1. Eschenbach, A:; Kastner, M.; Bierl, R.; Schaefer, G.; Morel, B. Chomosphere 1994, 28,683.

2. Saber, A.: Morel, G.; Paturel, L.: Jarosz, T.; Bonyer, M. M.; Vial, M. Fresenius J. Anal. Chem. 1991, 339. 716.

3. Freeman, J. I.; Mckee, R. H.; Phyllips, R. D. Toxicol Ind Health $1990,6,475$.

4. Grimmer, G.: Brume, H. J. Katl Cancer Inst 1987, 78,935.

5. Pyo, H. S.: Hong, I. E.: Lee, K. J.: Park, S. J.: Lee, W. Korean Anal Sci \& Tech 2000, 13,453.

6. Bonilla, N. B.; Vidal, J. L. M.; Frenich, A. G.; Gonzalez, R. R. Talonta $2009,78,156$.

7. Leite, N. F; Zamora, P. P: Grassi, M. T. I. Chromatogr: A 2008, $1192,273$.

8. Tones, K. C.; Stratford, J. A ; Waterhouse, K. S ; Furlong, E. T; Giger, W: Hites, R. A.; Schaffiner, C.; Tolunston, A. E. Emin. Sici. Technol. $1989,23,95$

9. Dong, M.; Locke, D. C.; Ferrand, E. Anat. Chemt 1976, $48,368$.

10. Freeman, D. J.: Catteil, F. C. R. Eminon. Sci. Techol. 1990, 24 , 1581.

11. Mallik, A. K.: Rahman, M. M.; Czann, M.: Takafuji, M.; Ihara, H. J. Chromatogr \& 2008, 1187, 119

12. Jinno, K.; Yamamoto, K.: Fetzer, J. C.: Biggs, W. R.: Wilton, R. T. Aicrocolum Sep. 1992, H(3), 187.

13. Mao, C.: McGill, K. E.; Tucker, S. A. J. Sep. Sci. 2004, 27(12), 991 .

14. Gautam, U. G.; Shundo, A.; Gautam, M. P.; Takafuji, M.; Ihara, H. Chrontatogr: A $2008,1189,77$.

15. Ryoo, J. J.; Kim, T. H.; Im, S. H.; Jeong. Y. H.; Park, T. Y.; Choi, S. H.; Lee, K. P; Park, J. H. J. Chrontatogr .4 2003, $987,429$.

16. Ryoo, J. T. Park, T. B.; Kwon, H. Y.; Lee, T. W. Bull. Kowan Chem. Soc. 2007, 28, 1042

17. Ryoo, J. J.; Amstrong, D. W. Bull. Korean Chem. Soc. 2007, 28, 2103.

18. Ward, T. I. Anal Chem 2006, 78, 3947.

19. Ryoo, J. J.; Song, Y.-A.; Park, J. Y.:Lee, K.-P.: Choi, S. H.: Hyun, M. H.; Ohta, K: Fujimoto, C.: Tin, J.-Y.: Takeuchi, T.: Lee, I. W. Bull. Korean Chem. Soc. 2006, $27,524$.

20. Ryoo, I. T.: Jeong, Y. H.: Lee, K.-P.; Han, S. O.: Lee, T. H.: Kuen, I. K.; Han, S. O.; Hyun, M. H. M ficrochemical Jomnal 2001, 68 , 127. 